\title{
ПРЕИМУЩЕСТВЕННЫЕ ПРАВА В РОССИЙСКОМ ГРАЖДАНСКОМ ПРАВЕ: ИСТОРИЯ, ТЕНДЕНЦИИ РАЗВИТИЯ, СОВРЕМЕННОЕ СОСТОЯНИЕ
}

\begin{abstract}
Аннотация: Предметом исследования является гражданско-правовое регулирование преимущественных прав в историко-правовом и теоретико-правовом аспектах, на примере отечественного законодательства соответствующих периодов в части определения предмета таких прав, их сущности, тенденций развития и преемственности регулирования. Автор подробно рассматривает случаи, когда действующее гражданское законодательство может отступать от принципа равенства, наделяя некоторых участников гражданского оборота исключительными правами и предоставляя им юридическое превосходство над прочими. Особое внимание в статье уделяется преимущественным правам в контексте развития корпоративного права. Методы исследования Автор подробно рассматривает вопросы темы с применением историко-правового и формально-правового анализа, исследование строилось на широкой источниковой базе ранее действовавщего и современного законодательства с привлечением и анализом классики российской цивилистики и современных доктринальных источников. Новизна и выводы. Особое внимание в статье уделено выявленной тенденции эволюиии правового регулирования преимущественных прав, как изъятий из общего закона - от сословных привилегий, ставивщих субъектов в исключительное положение (имперский период), до прав преимущественной покупки и порядка её реализации (в советский период). Сегодня преимущественные права классифицируются по двум группам: на заключение договора и на покупку (приобретение). Преимущественное право есть субъективное гражданское право, базирующееся на законе и гарантирующее возможность, преимущественно по отношению к иным лииам, совериать сделки по своему усмотрению.
\end{abstract}

Ключевые слова: Преимущественного, права, гражданского права, привилегии, собственность, Российская Империя, право собственности, имущественный оборот, ииркуляиия, гражданско-правовое регулирование. Abstract: The subject of this research is the civil legal regulation of priority rights within the historical-legal and theoretical-legal aspects on the examples of Russian legislation of the corresponding periods on the part of determination of the subject of such rights, their essence, development trends, and continuity of regulation. The author carefully examines the cases where the acting civil legislation can deviate from the principle of equality, granting priority rights to some parties of the civil process, and giving them legal advantage over others. A special attention is given to the priority rights in the context of development of corporate law, as well as to the detected trend of evolution of the legal regulation of priority rights as one that is taken out of the rest of the law-from class privileges, which gave subjects exclusive position (imperial period), to rights of priority purchase and order of its realization (during the Soviet period). The contemporary priority rights are classified by two groups: signing a contract, and purchase (acquisition). Keywords: Property turnover, right of ownership, Russian Empire, property, privileges, civil law, law, priority, circulation, civil-legal regulation.

азовым принципом российского гражданского права остается в соответствии с п. 1 ст. 1 ГК РФ[1], равный статус участников гражданских правоотношений, который обеспечивает гарантии равного положения участников оборота, без дискриминации и необоснованных преимуществ при реализации своих гражданских прав и обязанностей. Данный принцип развивает конституционные нормы о равенстве форм собственности. В данном случае действует общее правило о возможностях приобретения, реализации и прекращения прав собственности, а также иных вещных прав, включая их защиту. В то же время закон может допускать отступление от указанного принципа равенства, наделяя некоторых участников исключительными правами и предоставляя им определенное рамками закона превосходство над прочими субъектами гражданского оборота. Именно эти права считаются преимущественными.

Принято считать, что наиболее развитый и эффективный режим правового регулирования преимущественных прав (по крайней мере - в корпоративном праве) действует в Великобритании. Он сформировался как с развитием собственно права, так и в значительной мере, в результате деятельности институциональных инвесторов. В то же время, регулирование анализируемых прав в России нельзя считать чем-то новым или заимствованным. Исторически право преимущественной 
покупки было известно еще в Древней Руси. Ещё новгородские акты содержали нормы о солидарном обязывании покупателя не продавать части совместно приобретенного имущества, приходящей на его долю, с возможными исключениями.

В более позднем феодальном праве Московского государства право преимущественной покупки вошло в Соборное уложение 1649 г. (статья 17 «О вотчинах»), где регулировался порядок внутрисемейного наследования и распоряжения вотчинами, где просматривается усиление надзора и государственного регулирования. Уже в Соборном уложении сформировались положения, согласно которым любой участник общей собственности, был вправе сам распоряжаться принадлежащей ему долей, включая её отчуждение. В то же время, его соучастники пользовались преимущественным правом приобретения такой доли. Сформировавшись как гражданскоправовая традиция, данное положение перешло в Свод законов гражданских (Т. Х. Ч. І)[3].

В российской цивилистике классификацией преимущественных прав занимались К.П. Победоносцев и Д.И. Мейер. Традиционно русское, а затем и российское право относило преимущественные права, именуя их привилегиями (Т. І. Ч. 1. Ст. 71)[3], к правам, предоставляемым конкретному лицу в виде изъятия из общего закона, т.е. исключительные права [9, с. 260], которые проявлялись относились скорее не к частному праву как таковому, а более к сословному строю тогдашнего общества, системе социальных статусов и привилегий. Так, в ст. 71 Законов основных прямо закрепляла исключительный социальный статус таких прав: как привилегий, «дарованных верховной самодержавной властью частному лицу или обществу, изъемлют их от действия общих законов по тем предметам, по которым в этой привилегии содержатся точные определения» (Т. І. Ч. 1. Ст. 71) [3]. В связи с этим, можно сделать вывод о том, что к привилегиям законодательство Российской империи относило все изъятия из общих правил, ставящие субъектов привилегий в исключительное положение. С данным пониманием были связаны и предпринимаемые классификации привилегий, классической из которых считается классификация Д. И. Мейера[9, с. 260-263] по личным и потомственным, срочным и бессрочным, благоприятным и неблагоприятным (по степени улучшения/ ухудшения положения (статуса) субъекта привилегии).

В советский период традиционная регламентация преимущественных прав в целом сохранилась. В начале 1940 годов М.В. Змилева выдвинула тезис о невозможности существования права преимущественной покупки в советском праве, в силу неоправданности как общими задачами гражданского права, так и частными преимуществами сособственников, а также удобствами оборота. Автор исходил из того, что право преимущественной покупки вообще не соответствует принципам советского права и, соответственно противоречит им[7, с.75]. В целом, до середины 1960 годов устоялось позиция, согласно которой законодательная конструкция преимущественных прав лишь обременяла имущественный оборот, усложняя отчуждение доли в общем имуществе. В то же время, данная позиция подвергалась вполне обоснованной критике. Сторонники развития теории преимущественных прав как особого вида прав, исходили из того, что условия гражданского оборота необходимо приспособить к характеру права собственности, но никак не наоборот. Специалисты гражданского права подчеркивали потребность в дальнейшей доктринальной разработке данных вопросов.

Гражданский кодекс РСФСР 1964 г. (далее - ГК РСФСР) закрепил право преимущественной покупки и порядок её реализации. При продаже доли в общей собственности третьему лицу прочие участники общей долевой собственности получали право преимущественной покупки реализуемой доли по рыночной цене, за исключением продажи с публичных торгов. Мерой обеспечения реализации права преимущественной покупки ГК РСФСР содержал обязанность продавца доли письменно известить прочих участников общей долевой собственности о продаже своей доли стороннему лицу с указанием цены и прочих условий продажи. При этом прочие участники общей долевой собственности должны были реализовать данное право в сроки, определенные законом.

При игнорировании права преимущественной покупки иной долевой собственник в срок до трех месяцев был вправе в соответствием со статьей 120 ГК РСФСР требовать в судебном порядке перевода прав и соответствующих обязанностей покупателя. В то же время, в советской цивилистике теоретическое обоснование выделения преимущественных прав в отдельную группу появилось относительно поздно, в работах В.П. Грибанова, логично обосновавшего необходимость дифференциации преимущественных прав с выделением их в специальную группу прав, такую же как обязательственные, вещные, корпоративные и исключительные права[5, с.19]. Именно В.П. Грибанов дал четкое понимание преимущественных прав, как особых условий, при имеющихся равных условиях в целом, предоставляемых определенной законом группе лиц с установленными особыми признаками[5, с. 20]. 
С середины 1970 годов в гражданско-правовой литературе идет обсуждение исследуемой проблемы, по-разному определяется место преимущественных прав в общей системе гражданских прав, сохраняется дискуссия о правовой природе преимущественных прав, особенностям их возникновения, прекращения, осуществления и защиты. Современные авторы констатируют отсутствие теоретически обоснованного комплексного учения о преимущественных правах [10, c.38]. При этом разное понимание характера и природы преимущественных прав, присутствует как в гражданско-правовой науке, так и в правоприменении. В то же время, из общей совокупности преимущественных прав, исторически традиционным и наиболее применимым в советском гражданском праве оставалось преимущественное право приобретения доли из общей собственности.

В англо-саксонской правовой системе преимущественное право (pre-emption right) чаще всего обозначается как право первой покупки (first option to buy)[13, c.277]. В российской современной гражданско-правовой науке устоялась классификация преимущественных прав по двум основным группам: на заключение договора и на покупку (приобретение). Критерием в данном случае считается имущественный интерес управомоченного лица на заключение договора или приобретение имущества.

В действующем Гражданском кодексе РФ (далее - ГК РФ) перечень преимущественных прав существенно вырос по сравнению с ГК РСФСР. Сегодня при продаже доли в праве общей собственности иному лицу прочие участники долевой собственности сохраняют преимущественное право покупки реализуемой доли по цене продажи (ч. 1 ст. 250 ГК РФ). При этом действующее регулирование не предусматривает уступки преимущественного права покупки доли, которое распространяется как на движимое, так и на недвижимое имущество. ГК РФ прямо не относит преимущественное право ни к имущественным, ни к личным неимущественным правам, несмотря на то, что данный момент имеет существенное значение для вопросов о наследственного правопреемства.

Судебная практика сложилась так, что данное право причисляется к имущественным правам, допуская, таким образом, наследственное правопреемство. В данном случае суды разрешают сложные и не в полной мере урегулированные правом вопросы, например, об определении доли в недвижимости как незначительной. Судебная практика в данном случае опирается на усмотрение («по мнению Судебной коллегии...»), отмечая, что понятие «незначительности доли» относительно[14].
Наделение собственников имущества преимущественным правом необходимо для защиты интересов участников общей долевой собственности и возможного недопущения третьих лиц к владению, пользованию и распоряжению общим имуществом, равно как и интересом в увеличении своей доли. В то же время, ГК РФ (ст. 250) содержит срок, в течение которого прочие собственники вправе заявить намерение приобрести реализуемую долю в праве, как могут и отказаться от этого. При отказе остальных собственников долей от покупки реализуемой доли продавец поступает по своему усмотрению, продавая свою долю кому угодно. ГК РФ предусматривает, что при продаже доли с игнорированием преимущества покупки, другие участники долевой собственности в срок не более чем три месяца (пресекательный срок) обратиться в суд с требованием перевода на них прав и обязанностей покупателя.

В связи с недостаточной ясностью положений ст. 250 ГК РФ судебная практика, опираясь на широкое усмотрение, способствовала установлению порядка, по которому истец - участник долевой собственности, полагающий, что сделка нарушает его право преимущественной покупки, вносит на депозит суда сумму, равную цене договора купли-продажи, чем обосновывает серьезность своих претензий на заключение сделки, а также для компенсации расходов покупателя, купившего спорную долю. В то же время и данный порядок не является общепринятым и суд может потребовать выписку со счета с данной суммой или справку о наличии такой суммы на момент купли-продажи.

Областью реализации преимущественных прав являются современные корпоративные отношения. В зарубежной практике главным мотивом включения статей о преимущественных правах в корпоративное право и законодательство о фондовом рынке является потребность защиты акционеров от перераспределения капитала и сокращения доли контроля. В то же время, как обосновано отмечает Дж. Грант, преимущественное право способно мешать привлечения нового акционерного капитала и расширению базы акционеров[15, с.6]. В связи с этим в ЕС нередко звучат предложения об отмене режима преимущественных прав, как тормозящего развитие корпоративных отношений.

В корпоративной практике ЕС, США и Японии типичной формой преимущественного права является традиционно является право акционеров на приобретение новых акций, эмитированных Обществом. В этом контексте преимущественное право также именуют правом подписки или привилегией под- 
писки. Отметим, что это именно право, но никак не обязательство, акционеров приобрести новые акции, до их широкого предложения. Таким образом, акционеры могут поддерживать свои пропорциональные дол, предотвращая фондовые «разбавления». При этом в Великобритании право подписки автоматически предусмотрено законом, в других странах это может быть предусмотрено лишь учредительными документами Общества (США). В данном случае права акционеров нередко нарушаются, что является предметом судебных разбирательств[16, с. 538].

ГК РФ (ст. 66.3.) предусматривает, что по единогласному решению участников (учредителей) непубличного общества, в его устав может быть включен порядок реализации преимущественного права покупки доли в уставном капитале ООО или преимущественного права приобретения размещаемых АО акций (ценных бумаг, конвертируемых в его акции). Также ГК РФ наделил преимущественным правом покупки доли или части доли общества, участников ООО. Порядок реализации данного преимущественного права, а также срок, в течение которого участники общества могут воспользоваться своим правом, также законодательно закреплены[2].

При этом участники общества сохраняют свое преимущество в приобретении доли или её части участника общества в пропорции к объемам своих долей, в случае, если устав Общества не содержит другой порядок реализации преимущественного права покупки доли (части доли). В данном случае речь идет лишь об особенностях корпоративных отношений, которые не выходят за пределы их специфического регулирования и, соответственно не могут ставить их участников выше других категорий, которые не участвуют в указанных отношениях. Данная позиция косвенно уже нашла поддержку в литературе. В частности Ю.Г. Лескова отмечает, что указанный порядок предоставления кажущихся для всех преимуществ направлен на стимулировании экономической активности юридических лиц. Автор связывает это с владением участниками корпораций инсайдерской информацией, которой не владеют третьи лица, не участники корпорации[8, с.10]. По понятным причинам участники корпорации стремятся не допустить посторонних в число лиц, способных влиять на решения в корпорации.

Действующим законодательством (ст. 621 ГК РФ) преимущественное право предусмотрено и в части обязательств по передаче имущества. Так арендатор, добросовестно исполнявший договор аренды, по его истечении имеет преимущество в дальнейшем заключении нового договора аренды. Предпосылкой реализации преимущественного права в данном случае, считается письменное, в установленный срок, уведомление арендатором арендодателя о намерении подписать новый договор. Данное правило о преимущественном праве арендатора - диспозитивно, стороны вполне могут его исключить из договора.

Исторически преимущественные права всегда распространялись на наследование, где наследник, имевший совместно с наследодателем общую собственность на неделимое имущество или его долю, имел при разделе наследства преимущество на выделение в счет своей наследственной доли имущества, бывшего в общей собственности, перед теми наследниками, которые ранее не имели общую собственность, вне зависимости от пользования данным имуществом.

Таким образом, исходя из действующего гражданско-правового регулирования и устоявшегося доктринального понимания, полная реализация преимущественного права наследования требует соблюдения группы условий: имущество должно быть неделимо; наследодатель и наследник должны иметь право общей собственности; размер доли наследника может быть меньше или больше стоимости неделимого имущества. Потенциальная несоразмерность неделимого имущества с долей наследника купируется передачей наследником прочим наследникам иного имущества из общего состава наследства либо предоставлением другой компенсации, включая соответствующую денежную компенсацию (ст. 1170 ГК). ГК РФ (ст. 1168) определяет начало течения срока наличия или отсутствия права общей собственности на неделимое имущество, которым вероятно должен быть момент открытия наследства (ст. 1114 ГК РФ).

В целом преимущественное право всегда базируется на законе, является субъективным гражданским правом, опосредованным через правовую гарантию возможности преимущественно совершать сделки по своему усмотрению[12]. При этом преимущественное право закрепляется при наличии законного интереса участника соответствующих правоотношений социально особо (по сравнению с прочими) значимым или требующим особых юридических гарантий. Таким образом, для получения преимущественных прав необходимо получить предусмотренный действующим гражданским правом статус собственника, нанимателя, участника корпорации, наследника и т.д. При этом преимущественное право - всегда срочное. К правовым средствам защиты преимущественного права следует отнести признание недействительности сделки с последующим принудительным переводом прав и обязанностей по договору. 
Среди средств защиты преимущественного права следует отметить: признание недействительности сделки, принудительный перевод прав и обязанностей по договору, в случаях, когда это прямо предусмотренных законом. В судебной практике широко представлены вопросы регулирования преимущественных прав в трудовой сфере. По таким делам, как правило, предметом доказывания является преимущественное право на определенную работу, оставление на работе при оспаривании увольнения[17]. В современных условиях преимущественное право присутствует как вещных, так и в обязательственных правоотношениях, где оно подчиняется гражданско-правовым нормам, регулирующим конкретное отношение.

В условиях кризисного развития российской экономики и волатильности рынка в корпоративных отношениях преимущественное право имеет ключевое значение для акционеров, также оно важно в корпорациях, нацеленных на привлечение значительных средств при вторичном предложении. Базируясь на компаративном анализе можно отметить, что эффективность применения преимущественных прав для защиты миноритарных акционеров в целом определяется от действующей институциональной системы защиты их прав. Рассредоточение акционерного капитала после продажи новых акций аффилированным компаниям контролирующих акционеров - наиболее распространенный путь вытеснения миноритариев и стандартная форма вывода активов. Когда законодательство содержит жесткие нормы в отношении анализируемых прав, требующие большее, чем квалифицированное большинства (75\% акционеров) для отказа от введения режима преимущественных прав применительно к новой эмиссии акций (британская практика), такой правовой режим может обеспечить защиту миноритариям, если контролирующие акционеры имеют меньшее количество акций.

Преимущественные права, будучи определены и закреплены гражданским законом, представляются относительными и имеют обязательственный характер, реализуясь в обязательственных правоотношениях.

\section{Библиография:}

1. Гражданский кодекс Российской Федерации (часть вторая) от 26.01.1996 N 14-Ф3 (ред. от 29.06.2015)// Собрание законодательства РФ. 1996. N 5. Ст. 410; 2015. N 27. Ст. 4001.

2. Федеральный закон от 08.02.1998 N 14-Ф3 (ред. от 29.06.2015) «Об обществах с ограниченной ответственностью»// Собрание законодательства РФ. 1998. N 7. Ст. 785; 2015. N 27. Ст. 4001.

3. Свод законов Российской империи. Законы основные. Т. І. Ч. 1. СПб., 1907.

4. Блинков О.Е., Никольский С.Е. Преимущественные права в наследственном праве России и зарубежных стран. М.: Изд. гр. «Юрист», 2006. С. 54.

5. Грибанов В.П. Ответственность за нарушение гражданских прав и обязанностей// Осуществление и защита гражданских прав (серия «Классика российской цивилистики»). М., 2000. С. 294-295.

6. Диденко А.А. Понятие и система принципов гражданского права // Научный журнал КубГАУ. 2012. № 10(84). С. 67.

7. Зимелева В.М. Общая собственность в советском гражданском праве// Ученые записки ВИЮН. Вып. 2. М., 1941. С. 58.

8. Лескова Ю.Г. К вопросу о модернизации системы некоммерческих организаций: некоторые проблемные аспекты проекта изменений ГК РФ // Российская юстиция. 2013. № 1. С. 10-11.

9. Мейер Д.И. Русское гражданское право (изд. 1876 г.). М.: Статут, 2000. С. 63.

10. Пивовар Р.Е. Классификация преимущественных прав в гражданском праве // Юридический мир. 2007. № 2. С. 42.

11. Победоносцев К.П. Курс гражданского права. СПб., 1868. Ч. 1. Т. 2. С. 124.

12. Шайдуров И.В. Преимущественные права в российском гражданском праве // Научный журнал КубГАУ. 2014. № 103(09). С. 21.

13. Black's Law Dictionary. Ed. B.A. Garner St. Paul, Minnesota, USA: Thomson Reuters, 2009. P. 261-277.

14. Апелляционное определение Судебной коллегии по гражданским делам Кемеровского областного суда 33-12732/2015 от 08 декабря 2015 года Судебная коллегия по гражданским делам Кемеровского областного суда 33-12732/2015// РосПравосудие. Портал. Эл. ресурс https://rospravosudie.com/court-kemerovskij-oblastnoj-sud-kemerovskaya-oblast-s/act-501586768/

15. Грант Дж. Обзор теории и практики применения принципа преимущественных прав. EU/TACIS, 2005. 49 с.

16. Grechenig K. Discriminating Shareholders through the Exclusion of Pre-emption Rights? - The European Infringement Proceeding against Spain (C-338/06)// European Company and Financial Law Review (ECFR) 2007, P. 517-592.

17. Апелляционное определение Судебной коллегии по гражданским делам Новосибирского областного суда (дело $33-$ 10393/2015) от 1 декабря 2015 г.// РосПравосудие. Правовой портал https://rospravosudie.com/court-novosibirskij-oblastnojsud-novosibirskaya-oblast-s/act-501348019/; Апелляционное определение Судебной коллегии по гражданским делам Ростовского областного суда (дело № 33-18726/2015) от 3 декабря 2015 г.// https://rospravosudie.com/court-rostovskijoblastnoj-sud-rostovskaya-oblast-s/act-494110510/

\section{References (transliterated):}

1. Blinkov O.E., Nikol'skii S.E. Preimushchestvennye prava v nasledstvennom prave Rossii i zarubezhnykh stran. M.: Izd. gr. «Yurist», 2006. C. 54. 
DOI: $10.7256 / 1811-9018.2016 .2 .17446$

При цитировании этой статьи сноска на doi обязательна

Трансформация правовых и политических систем

2. Gribanov V.P. Otvetstvennost' za narushenie grazhdanskikh prav i obyazannostei// Osushchestvlenie i zashchita grazhdanskikh prav (seriya «Klassika rossiiskoi tsivilistiki»). M., 2000. S. 294-295.

3. Didenko A.A. Ponyatie i sistema printsipov grazhdanskogo prava // Nauchnyi zhurnal KubGAU. 2012. № 10(84). S. 67.

4. Zimeleva V.M. Obshchaya sobstvennost' v sovetskom grazhdanskom prave// Uchenye zapiski VIYuN. Vyp. 2. M., 1941. S. 58.

5. Leskova Yu.G. K voprosu o modernizatsii sistemy nekommercheskikh organizatsii: nekotorye problemnye aspekty proekta izmenenii GK RF // Rossiiskaya yustitsiya. 2013. № 1. S. 10-11.

6. $\quad$ Meier D.I. Russkoe grazhdanskoe pravo (izd. 1876 g.). M.: Statut, 2000. S. 63.

7. Pivovar R.E. Klassifikatsiya preimushchestvennykh prav v grazhdanskom prave // Yuridicheskii mir. 2007. № 2. S. 42.

8. Pobedonostsev K.P. Kurs grazhdanskogo prava. SPb., 1868. Ch. 1. T. 2. S. 124.

9. Shaidurov I.V. Preimushchestvennye prava v rossiiskom grazhdanskom prave // Nauchnyi zhurnal KubGAU. 2014. № 103(09). S. 21.

10. Grant Dzh. Obzor teorii i praktiki primeneniya printsipa preimushchestvennykh prav. EU/TACIS, 2005. 49 c.

11. Grechenig K. Discriminating Shareholders through the Exclusion of Pre-emption Rights? - The European Infringement Proceeding against Spain (C-338/06)// European Company and Financial Law Review (ECFR) 2007, P. 517-592. 